\title{
Reproductive physiology, and physical and sexual development of female offspring born to diabetic dams
}

\author{
Desenvolvimento físico, sexual e fisiologia reprodutiva \\ da prole feminina de ratas diabéticas
}

Raquel Spadotto', Débora Cristina Damasceno², Antonio Francisco Godinho ${ }^{3}$, Elaine Manoela Porto Amorim4, Juliana Elaine Perobelli ${ }^{5}$, Wilma De Grava Kempinas ${ }^{6}$

${ }^{1}$ Graduate Program in Geral and Applied Biology, Institute of Biosciences, Universidade Estadual Paulista (Unesp). Botucatu, Sao Paulo, SP, Brazil ${ }^{2}$ Department of Gynecology and Obstetrics, Botucatu Medical School, Unesp, Botucatu, Sao Paulo, SP, Brazil ${ }^{3}$ Centro de Assistência Toxicológica, Institute of Biosciences, Botucatu, Sao Paulo, SP, Brazil

${ }^{4}$ Center of Biological and Health Sciences (CCBS),, Universidade Estadual do Oeste do Paraná (Unioeste), Cascavel, PR, Brazi ${ }^{5}$ Graduate Program in Cellular and Structural Biology, Institute of Biology, Universidade Estadual de Campinas (Unicamp),

Campinas, SP, Brazil

${ }^{6}$ Department of Morphology, Institute of Biosciences, Unesp, Botucatu, Sao Paulo, SP, Brazil

Correspondence to: Wilma De Grava Kempinas Departamento de Morfologia, Instituto de Biociências, Unesp 18618-000 - Botucatu, SP, Brazil Caixa Postal 510

kempinas@ibb.unesp.br

Received on Feb/3/201 Accepted on Feb/17/2012

\begin{abstract}
Objectives: The objective of this study was to evaluate physical and sexual development and reproductive physiology in female rat offspring that developed in hyperglycemia conditions in utero and during lactation. Materials and methods: Maternal diabetes was induced in female rats by a single IV injection of streptozotocin before mating. Female offspring development was evaluated by means of the following parameters: physical development; age of vaginal opening and first estrus; weight and histological evaluation of uterus and ovaries; duration of the estrous cycle, sexual behavior, and fertility after natural mating. Results: In the female offspring, maternal diabetes caused delays in initial physical development; diminution in ovary weight and number of follicles; and inferior reproductive performance compared with the control group. Conclusions: The exposure to hyperglycemia in uterus and during lactation caused delays in physical and sexual development, and affected the reproductive physiology of female rats negatively. Arq Bras Endocrinol Metab. 2012;56(2):96-103
\end{abstract}

Keywords

Sexual behavior; physical development; diabetes; female reproductive physiology; female rat; streptozotocin

\section{RESUMO}

Objetivos: 0 objetivo deste estudo foi avaliar o desenvolvimento físico e sexual e a fisiologia reprodutiva de ratas que se desenvolveram em condições hiperglicêmicas in utero e lactação. Materiais e métodos: Para induzir o diabetes nas ratas, foi utilizada estreptozotocina em dose única via intravenosa antes do acasalamento. A prole feminina foi avaliada por meio dos seguintes parâmetros: o desenvolvimento físico; a idade de abertura vaginal e do primeiro estro, peso e avaliação histológica do útero e ovários; a duração do ciclo estral, o comportamento sexual e a fertilidade após acasalamentos naturais. Resultados: 0 diabetes materno provocou, na prole feminina, retardo no desenvolvimento físico; diminuição do peso dos ovários e do número de folículos; a performance reprodutiva foi inferior à do grupo controle. Conclusões: Concluiu-se que a exposição aos meios intrauterino e lactacional hiperglicêmicos provocou retardo no desenvolvimento físico e sexual e prejudicou a fisiologia reprodutiva de ratas. Ara Bras Endocrinol Metab. 2012;56(2):96-103

\section{Descritores}

Comportamento sexual; desenvolvimento físico; diabetes; fisiologia reprodutiva feminina; rata; estreptozotocina 


\section{INTRODUCTION}

$\mathrm{D}$ iabetes is a disease in which the body does not produce or properly uses insulin, causing hyperglycemia and affecting many organs (1). Diabetes in pregnancy is characterized by numerous disturbances in both development and fetal growth (2), and pregnant women with diabetes are more susceptible to miscarriages than non-diabetic women (3). Furthermore, diabetes is the principal cause of birth defects and perinatal mortality (4).

Several epidemiological $(5,6)$ and experimental studies (7-9) have demonstrated that the chances of developing glucose intolerance, obesity, insulin resistance, and type 2 diabetes mellitus in adulthood are higher among offspring of diabetic mothers (10), suggesting that fetal programming occurs during embryo-fetal development and is involved in diseases that may appear in adulthood (11). Programming is the term used to describe functional alterations through the course of postnatal life that result from a particular event that occurred in the initial stages of development (12).

Animal models to study the effects of diabetes during pregnancy have been utilized to characterize possible alterations in the development and function of the offspring organism that result from the effects of exposure to a metabolically abnormal intrauterine environment, independent of heredity (13). The most often used method to produce experimental diabetes is chemical induction by streptozotocin (STZ), a drug that is cytotoxic to pancreatic $\beta$-cells in different experimental animals (14) in a dose-dependent manner (15). Streptozotocin provokes, in rodents, a diabetogenic state that reproduces the clinical picture of type 1 diabetes mellitus that is decompensate in humans (16).

Diabetes is related to functional disturbances of the reproductive system in laboratory animals because it interferes with the hypothalamic-pituitary-gonadal axis (17). Female rats with streptozotocin-induced diabetes present diminution in the secretion of gonadotropins due to inadequate $\mathrm{GnRH}$ release, or a reduction in normal pituitary response when subjected to stimulation with this hormone (18).

The precise mechanisms by which diabetes provokes reproductive and fertility problems in women and laboratory animals have not been well elucidated. Thus, the present study aimed at evaluating the physical and sexual aspects of development, as well as the reproductive physiology during adulthood in female rats that developed in hyperglycemia conditions in utero and during lactation.

\section{MATERIALS AND METHODS}

\section{Animals}

Thirty male and 72 females Wistar rats both aged 30 days were supplied by the Multidisciplinary Center for Biological Investigation of the Universidade Estadual de Campinas, CEMIB, Unicamp. The animals were adapted and maintained throughout the experimental period in the Laboratory Animal Facility of the Department of Morphology in the Institute of Biosciences at Botucatu, Unesp, where they were housed in collective polyethylene cages $(43 \times 30 \times 15)$, under controlled conditions of temperature, maintained between $22^{\circ} \mathrm{C}$ and $25^{\circ} \mathrm{C}$, relative humidity of about $55 \%$ and $12-12$ hour photoperiod (light period beginning at $7 \mathrm{am}$ ), with free access to water and feed. The experimental period began when the animals were 90 days of age. The experimental protocol followed the Ethical Principles in Animal Experimentation adopted by the Brazilian College of Animal Experimentation (COBEA), and was approved by the Commission of Ethics in Animal Experimentation (CEEA) of the Institute of Biosciences at Botucatu (protocol 05/05).

\section{Experimental induction of diabetes in rats}

After acclimation, diabetes was induced in female rats with streptozotocin (SIGMA Chemical Company, St. Louis, MO, USA). STZ was administered intravenously (IV) into the tail vein, in a single dose of $40 \mathrm{mg} / \mathrm{kg}$ dissolved in citrate buffer $(0.1 \mathrm{M}, \mathrm{pH}$ 6.5), in female rats aged 90 days, weighting about $220 \mathrm{~g}$. Control rats received citrate buffer IV. Blood glucose concentrations were measured 7 days after diabetes induction. The threshold of normality was established at $120 \mathrm{mg} / \mathrm{dL}$ and glucose levels greater than this value were confirmed as hyperglycemia. The diabetic state was confirmed when blood glucose concentrations exceeded $200 \mathrm{mg} / \mathrm{dL}$. Only rats with glucose plasma levels $\geq 200$ $\mathrm{mg} / \mathrm{dL}$ were included in the diabetic group.

\section{Natural mating}

Eight days after diabetes mellitus was induced by streptozotocin, each female in estrus was placed in cages with one non-diabetic male rat during the dark period of the cycle to mate overnight. In the morning, males and females were separated and vaginal smears of each female were examined for the presence of sperm. The day when sperm was found in the vaginal smear was 
considered day 0 of gestation (GD 0). Timed-pregnant Wistar female rats were housed individually and observed daily for delivery. For indirect evaluation of maternal toxicity, rats were weighed on alternating days (from day 0 to 20 of gestation) to assess weight gain. On the mornings of GD $0,7,14$, and 21, blood samples were collected by puncture of the distal part of the tail to determine maternal glucose levels according to the procedures used during the diabetogenic period.

On day 20 post-conception, pregnant rats were observed until delivery. The day of delivery was defined as day 0 of postnatal life (PND). All rats were born by spontaneous vaginal delivery. On PND3, to ensure homogeneity of the study subjects, litters were standardized at six to eight pups per dam, with as many females as possible.

Rats that did not deliver were anesthetized and killed by decapitation; their uterus and ovaries were removed and corpora lutea, implantation sites, and resorptions were enumerated.

\section{Evaluation of female offspring after birth}

Reproductive development was evaluated in control and diabetic rats at different ages, in groups of 5 to 10 rats each, one or two per litter, to assess the following stages of sexual development: pre-puberty (postnatal day 30 - PND 30), puberty (PND 50) and sexual maturity (PND 80).

To prevent maternal rejection, pups were not evaluated at birth (19). Body weight and glucose levels of female offspring were evaluated at PND 3, 10, 20, and on the day they were killed.

To evaluate external physical aspects of female development, we utilized previously described methods (19). After the birth of the female offspring, the following parameters were observed daily from PND 3 to 20: body weight, eye-opening day, fur-appearance day, ear-unfolding day, and incisor-emergence day. To investigate puberty onset, we determined the average day of vaginal opening per litter. Observations started on PND 30.

To determine the age at first estrus, vaginal smears of all female rats were collected daily, starting on the day of puberty onset. For this purpose, $10 \mu \mathrm{L}$ of $0.9 \%$ saline were instilled into the vagina, and then aspirated (20). The material found in $10 \mu \mathrm{L}$ of physiological solution was analyzed under a phase-contrast microscope.

On PND 60, regularity of the estrous cycle was assessed via cells from vaginal smears collected over a period of 15 days, as previously described (20). Every morning, $10 \mu \mathrm{L}$ of $0.9 \%$ saline was instilled into the vagina, and then aspirated. The material was observed under a light microscope, and the phase of the estrous cycle was determined by cytology (21).

\section{Collection of reproductive organs}

After investigating the regularity of the estrous cycle, female rats in estrus were anesthetized and killed by decapitation. The ovaries and uteruses (with fluid) were collected from rats ( 5 female rats per experimental group), weighed and immersed in a fixative mixture $\left(85 \%\right.$ alcohol $80^{\circ}, 10 \%$ formaldehyde, and $5 \%$ acetic acid) for $24 \mathrm{~h}$. The tissues were embedded in Paraplast. Sections of $5 \mu \mathrm{m}$ were cut, and stained with hematoxylin and eosin (HE) for histopathology and morphometric analysis.

In the ovary, follicles were enumerated and classified; corpora lutea were also enumerated. Follicles were classified according to previous studies $(22,23)$. Primordial follicles and primary follicles were enumerated together and contained a single layer of either squamous or cuboidal epithelial cells. Follicles were classified as preantral when containing 2-4 layers of granulosa cells with no antral space. Antral follicles were defined by the presence of three or more layers of granulosa cells and a clearly defined antral space. Characteristics of atretic follicles included pyknotic granulosa cells, disorganized granulosa cells, degenerating oocytes, and detachment from the basement membrane.

\section{Sexual behavior}

On the first estrus after PND80, control ( $\mathrm{n}=7$, one per littler) and treated ( $n=7$, one per littler) female rats were used for the mating tests. Rats were maintained in an inverted 12-12h light-dark cycle. Animals were placed individually in polycarbonate clear cages measuring $56 \mathrm{x}$ $35 \times 31 \mathrm{~cm}$. For the evaluation of female sexual behavior, sexually experienced males were allowed ten mounts on the female, and the presence or absence of lordosis was observed. Results were expressed as the lordosis quotient (LQ, number of lordosis/ten mounts x 100).

\section{Reproductive physiology}

After the evaluation of sexual behavior, other sexually mature female rats were assessed in relation to fertility parameters. During a period equivalent to 3 sexual cycles ( 3 estruses), at most, 10 rats per experimental group, one or two per litter, were paired with previou- 
sly proven fertile males in their cages (one female per male), at the beginning of the morning period (inverted dark-light cycle). At the end of the afternoon, vaginal smears of each female were examined for the presence of sperm. The day when sperm was found in the vaginal smear was considered day 0 of gestation. On GD 20, females were anesthetized and killed by decapitation for collection of the uteruses and ovaries. Afterwards, corpora lutea and implantation sites were enumerated. Based on these results, the following parameters were determined: fertility potential (efficiency of implantation): implantation sites/corpora lutea $\mathrm{x}$ 100; gestation rate: number of pregnant females/ number of inseminated females x 100; rate of pre-implantation loss: number of corpus luteum - number of implantations/number of corpora lutea x 100; rate of post-implantation loss: number of implantations number of live fetuses/number of implantations x 100; sex ratio: number of male fetuses/number of female fetuses x 100 .

\section{Statistical analysis}

To analyze the percentages of pregnant females and those that presented gestation at term, Fisher exact test was utilized and data were expressed as percentages. To compare the rest of the parameters evaluated between the experimental groups, Student's $t$ test or Mann-Whitney test were utilized, depending on the nature of data distribution. Statistical analyses were carried out in Instat (version 3.0; GraphPad, Inc., San Diego CA, USA). Data were expressed as mean \pm standard error of mean (SEM) or median. Statistical significance was set at $\mathrm{p}<0.05$.

\section{RESULTS}

\section{Pregnancy results of female rats with induced diabetes}

Female rats with diabetes presented lower body-weight gain than those females with normal blood glucose. Mean blood glucose among female rats (Table 1) of the diabetic group, evaluated on DG $0,7,14$, and 20 was approximately $400 \mathrm{mg} / \mathrm{dL}$ (severe diabetes), while blood glucose of control animals was always lower than the maximum threshold of normality $(120 \mathrm{mg} / \mathrm{dL})$. Hyperglycemia was confirmed in dams throughout pregnancy (Table 1).
Table 1. Blood glucose concentrations $(\mathrm{mg} / \mathrm{dL})$ in diabetic and nondiabetic rats during pregnancy

\begin{tabular}{lcc}
\hline $\begin{array}{l}\text { Blood glucose } \\
\text { concentrations }(\mathbf{m g} / \mathbf{d L})\end{array}$ & $\begin{array}{c}\text { Non-diabetic group } \\
\mathbf{( n = 1 7 )}\end{array}$ & $\begin{array}{c}\text { Diabetic group } \\
(\mathbf{n}=\mathbf{5 5})\end{array}$ \\
\hline Day 0 & $111.16 \pm 3.64$ & $476.86 \pm 10.06^{\star \star \star \star}$ \\
Day 7 & $106.63 \pm 3.50$ & $468.71 \pm 1.77^{\star \star \star \star}$ \\
Day 14 & $96.94 \pm 2.75$ & $525.48 \pm 24.47^{\star \star \star \star}$ \\
Day 21 & $84.76 \pm 3.19$ & $561.32 \pm 13.43^{\star \star \star \star}$ \\
\hline
\end{tabular}

Values are expressed as mean \pm SEM. ${ }^{* \star \star \star} p<0.0001$, Mann-Whitney test.

\section{Evaluation of female offspring after birth}

Mean body weight $(\mathrm{g})$ of female offspring of diabetic female rats was significantly lower on PND 3, 10, and 20 than that of control female offspring (Table 2). Mean blood glucose $(\mathrm{mg} / \mathrm{dL})$ in offspring of diabetic female rats was statistically lower on PND 3 (Group 1 $=104.78 \pm 2.27$; Group $2=67.93 \pm 4.38)$ and PND 10 (Group $1=138.58 \pm 3.31$; Group $2=111.43 \pm$ 9.78 ), than values presented by control offspring, while on PND 20 blood glucose means were similar in both groups (data not shown).

There was a delay in the mean time (days) for ear unfolding, fur appearance, and eye opening in the offspring of diabetic females, compared with the control group. The time of incisor emergence did not differ significantly between groups (Table 3 ).

Table 2. Mean body weight (g) of litters, assessed on PND 3, 10, and 20

\begin{tabular}{lcc}
\hline \multirow{2}{*}{ Day } & \multicolumn{2}{c}{ Mean body weight $\mathbf{( g )}$ of litters } \\
\cline { 2 - 3 } & Group 1 $(\mathbf{n}=\mathbf{7})$ & Group 2 $(\mathbf{n}=\mathbf{7})$ \\
\hline PND 3 & $9.68 \pm 0.36$ & $6.48 \pm 0.39^{\star \star \star \star}$ \\
PND 10 & $23.13 \pm 0.52$ & $11.64 \pm 1.19^{\star \star \star \star}$ \\
PND 20 & $43.85 \pm 0.99$ & $22.37 \pm 2.55^{\star \star \star \star}$ \\
\hline
\end{tabular}

Group 1: litters of control rats; Group 2: litter of diabetic dams. Values expressed as mean \pm SEM. ${ }^{\star * \star \star} p<0.0001$, Student's $t$-test.

Table 3. Physical development of female offspring of control and diabetic rats

\begin{tabular}{lcc}
\hline \multirow{2}{*}{ Characteristics } & \multicolumn{2}{c}{ Mean (days) of physical development of } \\
litters
\end{tabular}

Group 1: litters of control rats; Group 2: litters of diabetic dams. Values expressed as mean \pm SEM. ${ }^{\dagger}$ Student's t-test; ${ }^{\ddagger}$ Mann-Whitney test. ${ }^{\star} p<0.05 ;{ }^{* *} p<0.01$. 


\section{Reproductive physiology}

Figure 1 shows a significant delay in time, in days, to vaginal opening, indicative of the onset of puberty, in the female offspring of diabetic female rats when compared with controls.

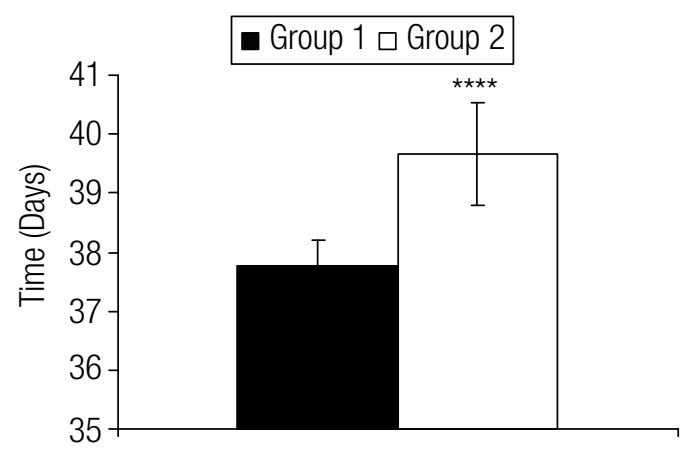

Figure 1. Age of the litters on the day of vaginal opening. Group 1: litters of control rats $(n=7)$; Group 2: litters of diabetic dams $(n=7)$. Values expressed as mean \pm SEM. Student's t-test. ${ }^{* \star \star \star} p<0.0001$.

Similarly, there was a delay in the day of first estrus among female offspring of diabetic female rats $(41.98 \pm$ $0.96)$ compared with control offspring $(36.02 \pm 0.45)$, but there was no difference between the frequency (in days) of pro-estrus, estrus or meta-estrus phases between groups (data not shown).

The histological aspects of ovaries and uteruses of female rats in estrus were similar in both experimental groups (data not shown). However, morphometric analysis of the gonads revealed significant diminution in the number of primordial/primary, pre-antral, and antral follicles of offspring of diabetic female rats compared with controls (Table 4). A reduction was also observed in mean absolute weight of the ovaries $(\mathrm{mg})$ among offspring of diabetic female rats in relation to the control group (Table 4).

Table 4. Absolute mean ovarian weight (mg); classification and counts of ovary structures

\begin{tabular}{lcc}
\hline \multicolumn{1}{c}{ Structures } & Group 1 $(\mathbf{n}=\mathbf{5})$ & Group 2 (n= 5) \\
\hline $\begin{array}{l}\text { Absolute mean weight of } \\
\text { ovaries (mg) }\end{array}$ & $174.25 \pm 7.15$ & $114.00 \pm 11.32^{\star \star \star}$ \\
$\begin{array}{l}\text { Primordial follicles and primary } \\
\text { follicles }\end{array}$ & $33.75 \pm 3.18$ & $10.63 \pm 2.05^{\star \star \star \star}$ \\
Pre-antral follicles & $21.13 \pm 2.15$ & $12.63 \pm 1.99^{\star}$ \\
Antral follicles & $13.25 \pm 1.72$ & $7.25 \pm 1.15^{\star}$ \\
Atretic follicles & $1.12 \pm 0.13$ & $0.75 \pm 0.16$ \\
Corpora lutea & $9.75 \pm 1.03$ & $7.75 \pm 1.37$ \\
\hline
\end{tabular}

Group 1: female offspring of control rats; Group 2: female offspring of diabetic dams, aged 60 days, in estrus. Values expressed as mean \pm SEM. ${ }^{\star} p<0.05,{ }^{* \star \star} p<0.001$ and ${ }^{\star \star \star \star \star} p<$ 0.0001 . Student's $t$-test.
The evaluation of sexual behavior did not show significant differences between the groups (data not shown). In relation to the reproductive performance of female offspring of diabetic rats, it was verified that exposure to an environment of diabetes in utero and during lactation provoked reductions in final weight of pregnant females, litter weight, and number of offspring, and elevation in placental weight compared with controls (Table 5).

Table 5. Mean blood glucose and fertility test

\begin{tabular}{|c|c|c|}
\hline Parameter & Group $1(n=10)$ & Group $2(n=10)$ \\
\hline${ }^{\mathrm{b}}$ Pregnancy rate (\%) & 90 & 80 \\
\hline a Mean blood glucose level (mg/dL) & $90.44 \pm 3.64$ & $82.75 \pm 3.19$ \\
\hline a Dam final body weight (g) & $321.80 \pm 7.65$ & $286.54 \pm 7.49^{\star \star}$ \\
\hline a Uterus + fetuses weight (g) & $60.99 \pm 5.41$ & $42.29 \pm 3.43^{*}$ \\
\hline 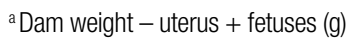 & $310.05 \pm 12.99$ & $264.23 \pm 7.25^{\star \star}$ \\
\hline a Fetal weight (g) & $3.71 \pm 0.32$ & $3.05 \pm 0.36$ \\
\hline a Placenta weight (g) & $0.51 \pm 0.03$ & $0.70 \pm 0.07^{\star}$ \\
\hline${ }^{a}$ Number of corpora lutea & $14.56 \pm 0.87$ & $13.13 \pm 0.64$ \\
\hline a Number of implantations & $11.00 \pm 0.80$ & $9.25 \pm 1.19$ \\
\hline${ }^{\text {a Number of resorptions }}$ & $1.11 \pm 0.26$ & $1.38 \pm 0.38$ \\
\hline a Number of fetuses & $10.33 \pm 0.89$ & $6.00 \pm 1.07^{\star \star \star}$ \\
\hline${ }^{\mathrm{b}}$ Sex ratio (\%) & 50 & 50 \\
\hline${ }^{\mathrm{b}}$ Fertility potential (\%) & 80.00 & 68.76 \\
\hline${ }^{b}$ Pre-implantation loss (\%) & 23.99 & 31.18 \\
\hline${ }^{\mathrm{b}}$ Post-implantation loss (\%) & 11.24 & 12.49 \\
\hline
\end{tabular}

Group 1: female offspring of control rats; Group 2: female offspring of diabetic dams. Values expressed as mean \pm SEM for Student's $t$-testa and as median for Mann-Whitney test ${ }^{t} .{ }^{*} p<$ $0.05,{ }^{\star \star} p<0.01,{ }^{\star \star \star} p<0.001$.

\section{DISCUSSION}

Diverse studies have demonstrated that the programming of the function of different body systems and organs occurs during intrauterine development. The results of this programming are manifested throughout life (fetal programming of adult diseases) in response to environmental disturbances in utero and during lactation $(10,24)$. Most of these studies involved the evaluation of the effects of fetal programming on cardiovascular dysfunctions and on the development of diabetes in adults due to gestation in an abnormal uterine environment (25). Given this context, the present study aimed at verifying the late effects of fetal/neonatal programming on female reproductive functions throughout development, and to demonstrate that the exposure of female rats to maternal diabetes during fetal development and lactation leads to consequences in 
female offspring that are manifested as much prior to puberty as during adulthood.

Among the parameters evaluated, body weight is highly important, since it provides a general view of the health status of the animal, and indicates possible effects of systemic toxicity. Although body weight gain among diabetic female rats in the present study was similar to that of controls throughout most of pregnancy, there was a diminution in body weight in the diabetic group at the end of this period. A recent study also observed that female rats in which diabetes was chemically induced with streptozotocin showed lower body weight gain during the pregnancy than the control group (25).

In the present study, gestation and reproductive success of diabetic female rats was impaired when compared with females with normal blood glucose. After the animals were killed, it was observed that the uteruses of diabetic female rats that did not deliver offspring revealed the presence of resorptions sites, indicating that chronic hyperglycemia in the intrauterine environment caused by maternal diabetes negatively affected offspring development and survival since the moment of conception. A recent study also reported an elevation in the rates of embryo resorption and fetal death among the offspring of diabetic female rats (26).

In this study of females with severe induced diabetes, it was observed that on PND 3, 10, and 20, mean body weight of female offspring was reduced when compared with control offspring, evidencing that their development was impaired. Epidemiological studies have demonstrated an association between low birth weight and development of chronic diseases in adulthood $(27,28)$. Mean blood glucose among female offspring born to diabetic female rats evaluated on PND 3 and 10 was lower than that of controls, probably due to an exacerbated response of pancreatic $\beta$-cells of pups on account of excessive hyperglycemia during intrauterine development (29).

In relation to physical development, delays in ear unfolding, fur appearance, and eye opening was observed in the present study among females born to diabetic dams. This might be related to intrauterine disturbances during pregnancy caused by maternal diabetes, negatively affecting fetal and neonatal growth and development, restricting intrauterine growth, characterized by low body weight at birth and at the beginning of the postnatal period $(30,31)$.

In recent decades, several studies have demonstrated a relationship between the restriction of intrauterine/ neonatal growth (RCIU) and pubertal development of females and males $(25,31)$. The relationship between the mechanisms that control the onset of puberty and the presence of RCIU has not been elucidated yet. Because of that, we performed an analysis of vaginal opening (32). Together with the first estrus, vaginal opening is an external sign of the onset of female puberty $(33,34)$. Our investigation showed that there was a delay in the mean age of vaginal opening and first estrus in offspring of diabetic female rats, suggesting that intrauterine/neonatal development in an hyperglycemic environment negatively affected initial sexual development in females. However, in adulthood, estrous cycle became normal.

Uterus weight and morphology underwent normal fluctuations due to the alterations in hormone levels that occur during the course of the estrous cycle, with maximum weight observed during pro-estrus in response to an increase in estrogen secretion (35). In the present study, the absence of changes in the regularity of the estrous cycle, in uterus morphology and weight during the estrus of adult female rats suggests that exposure to hyperglycemia in utero and during lactation did not interfere with neuroendocrine secretions during the reproductive cycle.

However, ovary weight was diminished in pubertal female offspring of diabetic dams, probably due to a reduction, at 60 days of age, in the number of primordial, primary, pre-antral, and antral follicles. These data suggest that exposure to hyperglycemic intrauterine and lactation environments may have induced, in this phase of sexual development, a discontinuous evolution of follicular stages, thus diminishing the ovulatory mechanism. The impact on reproduction is determined by the stage of follicular development achieved $(36,37)$.

Sexual organization of the female brain requires, during the sensitive period of development, low levels of estrogen of maternal origin to produce characteristic female sexual behaviors, as well as the cyclic release of gonadotropins to maintain the phases of estrus (38). In our studies, the lordosis coefficient of females during the sexual behavior test was similar in both experimental groups, suggesting that maternal hyperglycemia probably did not interfere with the sexual organization of the female brain.

As for the fertility tests, our study demonstrated a diminution in body weight among pregnant female offspring delivered by diabetic dams, and a reduction in the number of pups delivered by this group. This result is probably associated with premature loss of ovarian 
follicles provoked by damage in pre-antral and antral follicles, which temporarily interrupted reproductive physiology given the greater recruitment of primordial follicles to replace damaged follicles. Damage in primordial and primary follicles leads to permanent infertility, since they are not restored (39).

There was an increase in placental weight in female offspring of diabetic dams, a fact that could be related to a compensatory mechanism, whereas fetuses exposed to hyperglycemic intrauterine environment presented RCIU. However, this increase in placental weight was not sufficient to reverse the clinical picture of RCIU. These results corroborate studies of other authors (40).

\section{CONCLUSION}

In the present study, chronic hyperglycemia during gestation and lactation affected the reproductive functions of female offspring when they reached puberty and sexual maturity, reinforcing the hypothesis that environmental disturbances in utero and during lactation may permanently program the structure and function of the organism. Based only on the parameters evaluated, we cannot determine how the alterations found in the female reproductive system may have directly resulted from the hyperglycemic intrauterine and lactation environment, that is, whether they arose from maternal diabetes or from an indirect effect of a harmful maternal-fetal exchange that brought about nutritional deficiency and intrauterine restriction of offspring growth, since these two factors are related.

In this context, future studies to verify the mechanisms by which maternal diabetes affects reproductive parameters in offspring should be applied to human health to enable better pre- and perinatal care, thus ensuring better quality of life. Diabetes alters psychomotor development of female offspring born to diabetic dams; and the occurrence of this disorder has increased in recent decades throughout the globe, becoming an important public health problem. Thus, the utilization of animal models with experimentally-induced maternal diabetes (severe or gestational) may help elucidate the mechanisms by which the disease programs the fetal organism to develop chronic diseases and reproductive problems in later phases of life.

Acknowledgements: we would like to thank Fundação de Amparo à Pesquisa do Estado de São Paulo (Fapesp, Proc. 04/129480 and Proc. 04/15664-2) and Fundação para o Desenvolvimen- to da Universidade Estadual Paulista (Unesp) (Fundunesp, Proc. $01089 / 05$ ) for their financial support.

Disclosure: no potential conflict of interest relevant to this article was reported.

\section{REFERENCES}

1. ADA. Standards of Medical Care in Diabetes. Care. 2007;30:S4-S41.

2. Takenaka $Y$, Toyoda N. The effect of alpha 1-blocking vasodilator on fetal growth and uteroplacental blood flow in streptozotocin-induced diabetic rats. Life Sci. 1995;56(13):1127-34.

3. Reece EA, Coustan DR, Gabbe SG. Diabetes in women: adolescence, pregnancy and menopause. New York: Lippincott Williams \& Wilkins; 2004.

4. Zhao Z, Reece EA. Experimental mechanisms of diabetic embryopathy and strategies for developing therapeutic interventions. $J$ Soc Gynecol Investig. 2005;12:549-57.

5. Cho NH, Silverman BL, RizzoTA, Metzger BE. Correlations between the intrauterine metabolic environment and blood pressure in adolescent offspring of diabetic mothers. J Pediatr. 2000;136:587-92.

6. Manderson JG, Mullan B, Patterson CC, Hadden DR, Traub Al, McCance DR. Cardiovascular and metabolic abnormalities in the offspring of diabetic pregnancy. Diabetologia. 2002;45:991-6.

7. Canavan JP, Goldspink DF. Maternal diabetes in rats II: effects on fetal growth and protein turnover. Diabetes. 1988;37:1671-7.

8. Thamotharan M, McKnight RA, Thamotharan S, Kao DJ, Devaskar SU. Aberrant insulin-induced GLUT4 translocation predicts glucose intolerance in the offspring of a diabetic mother. Am J Physiol Endocrinol Metab. 2003;284:901-14.

9. FujisawY, NakagawaY, Ren-shan L, OhzekiT. Streptozotocin-induced diabetes in the pregnant rat reduces 11 beta-hydroxysteroid dehydrogenase type 2 expression in placenta and fetal kidney. Life Sci. 2004;75:2797-805.

10. Aerts $L$, Van Assche FA. Intra-uterine transmission of disease. Placenta. 2003;24:905-11.

11. Lesage J, Del-Favero F, Leonhardt M, Louvart H, Maccari S, Vieau $D$, et al. Prenatal stress induces intrauterine growth restriction and programmes glucose intolerance and feeding behaviour disturbances in the aged rat. J Endocrinol. 2004;181:291-6.

12. Heindel JJ. Role of exposure to environmental chemicals in the developmental basis of disease and dysfunction. Reprod Toxicol. 2007;23:257-9.

13. Boloker J, Gertz SJ, Simmons RA. Gestational diabetes leads to the development of diabetes in adulthood in the rat. Diabetes. 2002;51:1499-506.

14. Bolzán AD, Bianchi MS. Genotoxicity of streptozotocin. Mutation Research. 2002;512-21.

15. Holemans K, Aerts L, Van Assche FA. Lifetime consequences of abnormal fetal pancreatic development. J Physiol. 2003;574:11-20.

16. Hrabák A, Szabó A, BajorT, Körner A. Differences in the nitric oxide metabolism in streptozotocin-treated rats and children suffering from Type 1 diabetes. Life Sci. 2006;78:1362-70.

17. Baccetti $B$, La Marca A, Piomboni P, Capitani S, Bruni E, Petraglia $F$, et al. Insulin-dependent diabetes in men is associated with hypothalamo-pituitary derangement and with impairment in semen quality. Hum Reprod. 2002;17(10):2673-7.

18. Jhonson LM, Sidman RL. A reproductive endocrine profile in the diabetes (db) mutant mouse. Biol Reprod. 1979;20:552-9.

19. Smart JL, Dobbing J. Vulnerability of developing brain: II. Effects of early nutritional deprivation on reflex ontogeny and development of behavior in the rat. Brain Research. 1971;28:85-95. 
20. Marcondes FK, Bianchi FJ, Tanno AP. Determination of the estrous cycle phases of rats: some helpful considerations. Braz J Biol. 2002;62(4A):609-14.

21. Mandl AM. The phases of the oestrous cycle in the adult while rat. J Experimental Biology. 1951;28:576-84.

22. Borgeest C, Symonds D, Mayer LP, Hoyer PB, Flaws JA. Methoxychlor may cause ovarian follicular atresia and proliferation of the ovarian ephitelium in the mouse. Toxicol Sci. 2002;68:473-8.

23. Talsness CE, Shakibaei M, Kuriyama SN, Grande SW, Sterner-Kock A, Schnitker $P$, et al. Ultrastructural changes observed in rat ovaries following in utero and lactation exposure to low doses of a polybrominated flame retardant. Toxicol Lett. 2005;157:189-202.

24. Zambrano E, Martínez-Samayoa PM, Bautista CJ, Deás M, Guillén L, Rodríguez-González GL, et al. Sex differences in transgenerational alterations of growth and metabolism in progeny (F2) of female offspring (F1) of rats fed a low protein diet during pregnancy and lactation. J Physiol. 2005;566:225-36.

25. Zambrano E, Bautista CJ, Deás M, Martinez-Samayoa PM, Gonzalez-Zamorano $\mathrm{M}$, Ledesma $\mathrm{H}$, et al. A maternal low protein diet durin pregnancy and lactation in the rat male reproductive development. J Physiol. 2005a;563:275-84.

26. Al Ghafli MHM, Padmanabhan R, Kataya HH, Berg B. Effects of alpha-lipoic acid supplementation on maternal diabetes-induced growth retardation and congenital anomalies in rat fetuses. Mol Cell Biochem. 2004;261:123-35.

27. Soto IN, Mericq GV. Fetal growth restriction and insulin resistance. New findings and review of the literature. Rev Med Chile. 2005;133(1):97-104.

28. Srinivasan M, Aalinkeel R, Song F, Mitrani P, Pandya JD, Strutt $B$, et al. Maternal hyperinsulinemia predisposes rat fetuses for hyperinsulinemia, and adult-onset obesity and maternal mild food restriction reverses this phenotype. Am J Physiol Endocrinol Metab. 2006;290(1):129-34.

29. Van Assche FA, Holemans K, Aerts L. Long-term consequences for offspring of diabetes during gestation. Br Med Bull. 2001;60:173-82.
30. Holemans K, Gerber RT, Meurrens K, Clerck F, Poston L, Van Assche FA. Streptozotocin diabetes in the pregnant rat induces cardiovascular dysfunction in adult offspring. Diabetologia. 1999;42:81-9.

31. Engelbregt MJ, Houdijk ME, Popp-Snijders C, Delemarre-Van de Waal HA. The effects of intra-uterine growth retardation and postnatal undernutrition on onset of puberty in male and female rats. Pediatr Res. 2000;48(6):803-7.

32. Eckstein $\mathrm{KL}$, Oberlander SG, Marx GF. Uterine rupture during extradural blockade. Can Anaesth Soc J. 1973;20(4):566-8.

33. Ojeda SR, Urbanski HF. Puberty in the rat. The physiology of reproduction. New York: Raven Press; 1994. p. 363-409.

34. Beckman DA, Feuston M. Landmarks in the development of the female reproductive system. Birth defects research. Part B. Dev Reprod Toxicol. 2003;68(2):137-43.

35. US EPA. Guidelines for ReproductiveToxicity Risk assessment, U.S. Environmental Protection Agency. Federal Register; 1996. p. 61-212.

36. Hoyer PB, Sipes IG. Assessment of follicle destruction in chemical-induced ovarian toxicity. Annu Rev Pharmacol Toxicol. 1996;36:307-31.

37. Hoyer PB. Ovotoxic environmental chemicals: indirect endocrine disruptors. In: Naz R (ed). Endocrine disrupters: effects on male and female reproductive systems. CRC Press. Boca Raton. 1999;57-88.

38. Dohler KD, Cocquelin A, Davies F, Hines M, Shrne JE, Gorski SA. Differentiation of the sexually dimorphic nucleus in the preoptic area of the brain is determined by the perinatal hormone environment. Neurosciences Letters. 1982;33:295-8.

39. Hooser SB, Douds DP, DeMerell DG, Hoyer PB, Sipes IG. Long-term ovarian and gonadotropin changes in mice exposed to 4-vinylcyclohexene. Reprod Toxicol. 1994;8:315-23.

40. Rudge, MVC, Damasceno DC, Volpato GT, Almeida FCG, Calderon IMP, Lemonica IP. Effect of Ginkgo biloba on the reproductive outcome and oxidative stress biomarkers of streptozotocin-induced diabetic rats. Braz J Med Biol Res. 2007;40:1095-9. 